\section{Duesberg: rights and wrongs}

SIR - I have no quarrel with the policy that gives an editor freedom to publish or to reject whatever material may be submitted to him, but for him to reject an intended publication and then to subject its author to the kind of criticism levelled at Dr Peter Duesberg in your recent leading article (Nature 363, 109; 1993) seems to me at best unnecessary and at worst grossly unfair.

I am no friend of Duesberg, or of his campaign on the causation of AIDS, but your treatment smacks of the "nonreligious Inquisitions of the twentieth century" referred to by Psimopoulos and Theocharis, ironically in the same issue of Nature $(363,108 ; 1993)$, in their comments on the Vatican's tardy rehabilitation of Galileo.

\section{J. Silvester}

MRC Cyclotron Unit,

Hammersmith Hospital,

Du Cane Road, London W12 OHS, UK

SIR - You state that Peter Duesberg wrongly uses tendentious arguments to confuse understanding of AIDS, that his debating technique is intolerable because he asks unanswerable rhetorical questions and that he should stop. The tone and logic of your leading article seem inappropriate to a scientific journal, and Nature's position on Duesberg's theory seems prejudiced.

The rhetorical questions Duesberg has posed are in fact statements - that the widely accepted hypothesis that HIV is the cause of AIDS is not consistent with the facts. If, for instance, someone asks the question "Why cannot the theory explain the facts A, B, C . . ?", that is not only a stimulant of further research, but a serious objection against the theory.

The reasoning behind Duesberg's theory occupies 60 pages of text and refers to more than 600 papers by other authors (Pharmac. Ther. 255, 201-277;1992). The attempt to prove that the theory is wrong, based on references to a few studies by Duesberg's opponents, is not persuasive: there are no criteria to estimate these as more authentic than those to which Duesberg refers.

You state that Duesberg's work has not been published because it conflicts with Nature's obligation to provide readers with authentic information. Duesberg adduces data from works of other authors and official sources of statistical information to support his theory. In effect, his work expresses original interpretations of well-known and published facts, and the statement that the work does not meet the criterion of authenticity is at variance with logic.

It is clear from the context that the decision to reject the work is based on the conclusions of referees. It is quite easy for an editor to predict the negative response of a referee to an unorthodox work, and the choice of referee(s) is almost equivalent to a final decision to reject the work.

The real motives for the rejection of Duesberg's paper remain unclear. Neither the peculiarities of his rhetorical style nor "non-authenticity of information" can explain why the paper has been rejected. The real cause seems to be connected with the question (non-rhetorical and answerable) of whose interests may suffer if Duesberg's theory is true.

Duesberg's paper highlights a much more general problem: the effectiveness of the procedures used by scientific journals to select papers for publication. Even for ordinary works, the modern system seems ineffective (see, for example Ernst et al. Nature 363, 296; 1993). If a work expresses an unorthodox view, its chance of being published is quite small. As the history of science demonstrates, most landmark works have been at first regarded as wrong and intolerable. Open discussion of this problem in Nature's pages would be very useful.

Kv.128, 162-G Tractorostroiteley Ave, Kharkov, 310129, Ukraine

SIR - We congratulate you on the leading article in News and Views on Duesberg's right of reply. We have both been acquainted with Duesberg since the early 1970 s, and agree that his high-calibre research papers published before he became a campaigner should not be forgotten. However, in this respect, the general reader should keep in mind that, in addition to his campaign against HIV, Duesberg's views on the existence of oncogenes also conflict with what is generally accepted as the most reasonable and scientifically sound explanation of cellular carcinogenesis.

Given his early successes, one can only speculate sadly on the excellent contributions Duesberg might have made in the past decade had he chosen not to follow the path of righteousness (or wrongness, as the case may be). On HIV and AIDS, Duesberg has certainly raised cogent questions about the pathogenesis of the disease, as have many other scientists who have followed the more accepted path: first the question, then the experiments and then the conclusions. A recent report in Nature by Pantaleo et al. (362, 355--359; 1993) provides an excellent example of how a great deal of arduous work contributes to solving the mystery of locating HIV when we can't detect it in the blood. In the past decade, Duesberg has published very little material to back up his claims. Recently, he has regrettably

\section{v. Kolladin}

moved one step beyond campaigning, by making false accusations against scientists who do not happen to share his beliefs. These colleagues have adequately answered back (see The Lancet 341, 12221224; 1993). A. G. Dalgleish's last paragraph is rather strongly worded, but it spells out the present unfortunate situation.

Your subtitle ends: "He should stop". Or, we submit, "should he be stopped?" For example, should he somehow be prevented from appearing on television to misinform individuals who are at risk from the disease? One approach would be to refuse television confrontations with Duesberg, as Tony Fauci and one of us managed to do at the opening day of the VIIth International Conference on AIDS in Florence. One can't spread misinformation without an audience.

Luigi Chieco-Bianchi

Institute of Oncology,

University of Padova, Padova, Italy

Glovanni B. Rossi

Laboratory of Virology,

Istituto Superiore di Sanità, Rome, Italy

\section{Eppur si muove}

SIR - Psimopoulos and Theocharis ${ }^{1}(\mathrm{Na}$ ture 363,108 ; 1993) point to possible error in Galileo's contention of the "triumph absolutely" of the Copernican theory. They cite Einstein's coordinate relativity to question whether one can say the Earth moves about the Sun or vice versa. But the essence of the Copernican model is that the Earth and the other planets revolve around the Sun, rather than older tradition that the Sun and the other planets revolve around the Earth. The two models differ in this essential topology, and cannot be converted by any reasonable geometric translation. Galileo's essential contention was the incorrectness of the theological model: an immovable Earth at the centre of the Universe, with the Sun and planets in their orbits about it.

Regardless of the relativity of coordinate systems, in the Copernican sense, eppur si muove.

\section{Keith Conover}

36 Robinhood Road, Pittsburgh,

Pennsylvania 15220-3014, USA

\section{Academic equality}

SIR - "If top universities truly want to be seen to lead the field in sex equality . . .": so Nature on 27 May $(363,288 ; 1993)$. But surely what is needed is equality of opportunity. One may hope that this will lead to equality of achievement, but possibly it may not, and it cannot be taken for granted that the two must be the same. C. B. Goodhart Gonville \& Caius College, Cambridge CB2 1TA, UK 